\title{
Epstein-Barr virus encoded latent membrane protein 1 regulates mTOR signaling pathway genes which predict poor prognosis of nasopharyngeal carcinoma
}

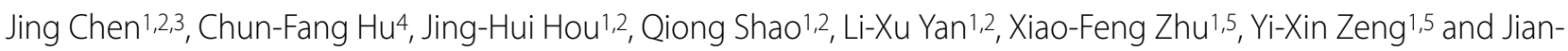
Yong Shao*1,2,5

\begin{abstract}
Background: The oncoprotein Epstain-Barr Virus (EBV)-encoded latent membrane protein1 (LMP1) modulates the pathological effects of the NF-KB, AP-1 and JAK/STAT pathways in nasopharyngeal carcinoma (NPC).

Methods: Microarray analysis was performed on the NPC cell line HONE1 stably transfected with a LMP1-expression plasmid or an empty vector. Based on assigned pathways analyzed using the KEGG database, the mTOR signaling pathway was selected for verification by quantitative RT-PCR. Western blot, RNA interference and immunofluorescence were used to determine the relationship between LMP1 and mTOR signing pathway genes, and their clinical significance to NPC.

Results: Our studies revealed that overexpression of LMP1 upregulated the MTOR signaling pathway, possibly through phosphorylation of AKT/mTOR/P70S6K/4EBP1 in the NPC cell lines HONE1 and 6-10B. Knockdown of LMP1 reduced expression of p-mTOR and p-4EBP1 in EBV-positive NPC cell line C666-1. In addition, LMP1 expression closely correlated with expression of $p-m T O R, p-P 70 S 6 K$ and p-4EBP1 in NPC tumors. Expression of p-P70S6K, p-4EBP1 and LMP1, but not $p$-mTOR, significantly correlated with overall survival of NPC patients. However, only LMP1 was an independent prognostic factor.

Conclusions: These results suggest that the mTOR signaling pathway is regulated by LMP1 expression in NPC. LMP1 and the genes in the mTOR pathway such as p-P70S6K and p-4EBP1 may be potential prognostic biomarkers.
\end{abstract}

\section{Background}

Nasopharyngeal carcinoma (NPC) is a unique cancer of the head and neck that has a high incidence in Southern China, where it is endemic, at 25 cases per 100,000 person-years in the Guangzhou area [1]. Most NPC patients can be cured if the disease is diagnosed and treated at an early stage. However, the long-term survival rate of NPC patients with advanced stage cancer is still very poor, with a median survival time for patients with distant metastasis of only 9 months [2].

\footnotetext{
* Correspondence: shaojy@sysucc.org.cn

1 State Key Laboratory of Oncology in Southern China, Sun Yat-Sen University Cancer Center, Guangzhou, China

Full list of author information is available at the end of the article
}

Epstein-Barr virus (EBV) is a human herpesvirus that has been intimately associated with both lymphoid and epithelial malignancies including lymphoma, NPC and gastric cancer [3]. NPC tumor cells express a limited set of EBV latent genes including EBV nuclear antigen 1, latent membrane proteins (LMP1, LMP2A, LMP2B), and EBV-encoded small RNA [4]. Of these genes, LMP1 has been identified as encoding an oncoprotein that is thought to be a key modulator in NPC pathogenesis. In NPC, LMP1 contributes to invasion and metastasis by inducing expression of matrix metalloproteinase 9 (MMP9)[5]. In addition, LMP1 may mediate various pathological effects such as promotion of cell proliferation, metastasis and inhibition of apoptosis in NPC [6]. As a member of the tumor necrosis factor receptor super- 
family, LMP1 expression can activate the nuclear factorkappa B (NF-kB), activator protein 1 (AP-1) and employing Janus kinases (JAKs) or and signal transducers and activators of transcription (STATs) (JAK/STAT) pathways and regulate their substrates[6]. LMP1 also targets the phosphatidylinositol-3-kinase (PI3K)/AKT pathway to induce fibroblast transformation and enhance cell survival $[7,8]$. Moreover, LMP1 can promote epithelial cell motility and enhance invasiveness by activating the extracelluar signal-regulated kinase/mitogen-activated protein kinase (ERK-MAPK) pathway [9].

Mammalian target of rapamacin (mTOR) is an evolutionarily conserved serine/threonine protein kinase with an important role in cell growth and proliferation through regulation of ribosome biogenesis and protein translation [10]. PI3K/AKT is considered a critical upstream mediator of the mTOR signaling pathway. The characterized downstream effectors of mTOR are ribosomal protein S6 kinases (P70S6K), and eukaryotic initiation factor $4 \mathrm{E}$ (eIF4E)-binding protein (4E-BP1), with eIF4E dissociating from 4E-BP1 to initiate translation after 4E-BP1 phosphaorylation, while P70S6K translates mRNA transcripts with a 5'-TOP motif following hyperphosphorylation by mTOR $[11,12]$.

To further clarify the signaling pathways regulated by LMP1 in NPC, we investigated the association between the mTOR signaling pathway and LMP1, the expression of p-mTOR, $\mathrm{p}-\mathrm{P} 70 \mathrm{~S} 6 \mathrm{~K}$ and $\mathrm{p}-4 \mathrm{EBP} 1$, and their relationship to clinicopathologic parameters of NPC patients.

\section{Materials and methods}

Patients and tissue samples

For this retrospective study, archival formalin-fixed, paraffin-embedded specimens from 230 primary NPC patients admitted from 1992-2002 to the Sun Yat-Sen University Cancer Center (Guangzhou, China) were recruited. All NPC samples were obtained before treatment with standard curative radiotherapy, with or without chemotherapy. Sixty patients were diagnosed as differentiated non-keratinized (WHO types II), and 170 patients had undifferentiated carcinoma (WHO type III). According to the Chinese 1992 staging system [13], patients were classified as 6 in stage I, 49 in stage II, 110 in stage III, 65 in stage IV. The majority of patients were male (173 of 230 , or $75.2 \%$ ), ranging from 86 to 14 , with a median age of 46. This study was approved by the Research Ethics Committee of the Sun Yat-Sen University Cancer Center (Reference number: YP2009167).

\section{Tissue microarray construction}

Paraffin-embedded specimens were from a previously constructed tissue microarray. Protocols and instruments for the tissue array construction were described previously [14].

\section{Immunohistochemistry}

The immunohistochemistry (IHC) protocol was as described previously [14]. Briefly, tissue sections were dewaxed for antigen retrieval, and incubated with primary antibodies LMP1 monoclonal antibody (CS 1-4, Neomarkers, USA) at a dilution of 1:50, or p-mTOR (Ser2448), p-P70S6K (Thr389), or p-4EBP1 (Thr70) (Cell Signaling, USA) at dilutions of 1:100 overnight at $4^{\circ} \mathrm{C}$. Detection was with a Catalyzed Signal Amplification Kit (DAKO Co, Carpinteria, USA) and visualization was with 3, 3'-diaminobenzidine (DAB).

IHC results were evaluated and scored independently by two pathologists without knowledge of patient clinicopathological outcomes. IHC expression levels for LMP1, p-mTOR, p-P70S6K and p-4EBP1 were assessed by a semi-quantitative scoring system according to the intensity of staining and percentage of tumor cells stained. Staining intensity was scored as $0=$ negative, $1=$ weak, 2 $=$ moderate, $3=$ strong. The percentage of tumor cells stained was scored as $0=$ no tumor cells stained, $1=1$ $10 \%$ of tumor cells stained, $2=11-50 \%$ of tumor cells stained, $3=51-100 \%$ of tumor cells stained. The two individual parameters were added, resulting in an immunoreactivity score (IRS) ranging from 0 to 6 . We defined cases with IRS $\geq 4$ as high expression, and cases with IRS $<4$ as low expression.

\section{Cell culture and plasmids}

The EBV-negative human NPC cell lines HONE1 and 610B, and the EBV-positive NPC cell line C666-1 were incubated in RPMI-1640 medium supplemented with $10 \%$ fetal bovine serum (FBS) (Gibco, USA), 100 units of penicillin $/ \mathrm{ml}$ and $100 \mu \mathrm{g}$ of streptomycin $/ \mathrm{ml}$. All cells were maintained in a humidified incubator at $37^{\circ} \mathrm{C}$ with $5 \% \mathrm{CO}_{2}$.

The eukaryotic expression plasmid pZipNeoSV-LMP1 containing the B95.8-LMP1 gene was kindly provided by Professor Kai-Tai Yao from Nan Fang Medical University (Guangzhou, China) [15].

\section{Transient and stable transfection}

Briefly, $4 \times 10^{5}$ cells per well were plated into six-well plates and grown for one day in antibiotic-free medium containing $10 \%$ FBS prior to transfection. Plasmid pZipNeoSV-LMP1 and control vector transfection were performed with Lipofectamine 2000 (Invitrogen, CA) according to the manufacturer's instructions. Further assays were conducted after $48 \mathrm{~h}$ incubation of transiently transfected cells.

To generate the stable transfected cell lines HONE1LMP1 and HONE1-vector, cells were passaged at 1:6 into fresh growth medium $24 \mathrm{~h}$ after transfection. G418 (Amresco, USA) at a final concentration of $150 \mu \mathrm{g} / \mathrm{ml}$ was 
added to complete medium to select resistant cells. Clones were separated and expanded into stable cell lines.

\section{Western blot analysis}

Transfected cells were harvested and lysed with RIPA buffer (Upstate, USA). Denatured proteins were separated by SDS-PAGE electrophoresis and transferred to PVDF membranes (Roche, Germany), and incubated with primary antibodies LMP1 (BD, USA), p-IKB $\alpha$, phosphatase and tensin homolog (PTEN), Poly ADP-ribose polymerase (PARP), Survivin, AKT1, p-AKT (Thr308) (Santa Cruz, USA), mTOR, p-mTOR(Ser2448), pP70S6K(Thr389), p-4EBP1 (Thr70) (cell signaling, USA) and p-NF-kB p65 (Ser276) (Kangchen, China) overnight at $4{ }^{\circ} \mathrm{C}$ in $5 \%$ skimmed milk/TBST (Tris-buffered saline solution containing $0.1 \%$ Tween 20 ) at a dilution of 1:1000. GAPDH (1:3000 dilution, Santa Cruz, USA) was used as internal control. Horseradish peroxidase-conjugated second antibody incubation was followed by chemiluminescence detection with an ECL Western blot Kit (Cell Signaling Technology, USA). Densitometry to quantify proteins was conducted by Image $\mathrm{J} 1.37 \mathrm{v}$ software (NIH, USA).

\section{RNA extraction}

Total RNA was isolated by Trizol (Invitrogen, CA) and purified by Nucleospin RNA clean-up (MN, USA). All procedures were performed according to the manufacturer's instructions. Formaldehyde agarose gel electrophoresis was carried out to quantify the total RNA.

\section{CDNA microarray analysis}

The human $22 \mathrm{~K}$ oligonucleotide microarray comprised 21,329 probes from the Operon Company (Human Genome Oligo Set Version 2.1), constructed by CapitolBio Corporation (Beijing, China). Hybridization to each array was performed with equivalent amounts of HONE1-LMP1 and control HONE1-vector samples that were differentially fluorescence-labeled with $\mathrm{Cy} 3$ or $\mathrm{Cy} 5$. Fluorescence exchange experiments were performed. Hybridization and image capture were as previously described [16]. Normalization was based on a LOWESS program [17]. All original data was submitted to the Gene Expression Omnibus http://www.ncbi.nlm.nih.gov/projects/geo/ with the accession number GSM467646. Genes with signal intensity $(\mathrm{Cy} 3$ or $\mathrm{Cy} 5)>800$ were regarded as expressed, and alteration ratios above 1.3-fold, or lower than 0.7, were defined as differential expression. Pathways analysis of all differentially expressed genes was performed according to the Kyoto Encyclopedia of Genes and Genomes (KEGG) database.

\section{Quantitative real-time PCR (Q-RT-PCR)}

To validate the microarray results, five genes associated with the mTOR signaling pathway were analyzed by QRT-PCR. Primers were designed by Primer 5.0 (Addi- tional file 1). Following the manufacturer's protocols, cDNA was prepared from $2 \mu \mathrm{g}$ total RNA by M-MLV reverse transcriptase (Promega, USA) and amplified with a DNA Master SYBR Green I Kit (Roche, Germany). The relative expression ratio was determined by the formula $2^{-\Delta \Delta \mathrm{Ct}}\left(\Delta \Delta \mathrm{Ct}=\Delta \mathrm{Ct}_{\mathrm{HONE1}-\mathrm{LMP1}_{1}-\Delta \mathrm{Ct}_{\mathrm{HONE1}} \text {-Vector }}, \quad \Delta \mathrm{Ct}=\right.$ $\mathrm{Ct}_{\text {gene }}-\mathrm{Ct}_{\mathrm{GAPDH}}$, where $\mathrm{Ct}$ is the cycle number at which the fluorescence signal exceeds background) [18].

\section{Small interfering RNA (siRNA) transfection}

The LMP1 and negative control siRNA were chemically synthesized by GenePharma Corporation (Shanghai, China). The sequences of LMP1 siRNA (EU000388, miRNA nucleotide 371-389) were: sense sequence, 5'GGA AUU UGC ACG GAC AGG CTT-3'; anti-sense sequence, 5'-GCC UGU CCG UGC AAA UUC CTT-3' $[19,20]$. The sequences of negative control siRNA were: sense sequence, 5'-UUC UCC GAA CGU GUC ACG UTT-3'; anti-sense sequence, 5'-ACG UGA CAC GUU CGG AGA ATT-3'. The EBV-positive NPC cell line C666-1 was seeded in a 24 -well plate with $4 \times 10^{4}$ cells per well in growth medium without antibiotics the day before transfection. Following the manufacturer's instruction, 1 $\mu$ Lipofectamine2000 was used in each well with final siRNA concentration at $50 \mathrm{nM}$ or $100 \mathrm{nM}$.

\section{Immunofluorescence assay}

After $72 \mathrm{~h}$ of siRNA transfection, cells were harvested and washed thrice with PBS, suspended in PBS and centrifuged on the slides. Slides were fixed with $4 \%$ paraformaldehyde for $30 \mathrm{~min}$, permeabilized, and cells covered with $0.1 \%$ Triton X-100 for 15 min. After $1 \mathrm{~h}$ blocking in PBS $+0.1 \%$ Tween plus $1 \%$ bovine serum albumin, cells were incubated with primary antibodies of LMP1 (BD, USA), p-mTOR (Ser2448) and p-4EBP1 (Thr70) (Cell Signaling, USA) at $4^{\circ} \mathrm{C}$ overnight, then with secondary antibody for $1 \mathrm{~h}$ at room temperature. After counterstaining with DAPI $(1 \mu \mathrm{g} / \mathrm{ml})$ for $10 \mathrm{~min}$, slides were observed and photographed with confocal microscopy.

\section{Statistical analysis}

Data was analyzed using SPSS16.0 software (SPSS Inc., Chicago, USA). The correlation between LMP1, pmTOR, p-P70S6K, p-4EBP1 expression and clinicopathological parameters was assessed by chi-square test. The correlation between LMP1 and p-mTOR, p-P70S6K, p4EBP1 expression was measured by Spearman's correlation test. Kaplan-Meier analysis and log-rank test were used to assess survival rate and compare survival rate differences. Univariate and multivariate regression analysis were performed with the Cox proportional hazards regression model to analyze the factors related to prognosis. A $p$-value less than 0.05 was considered statistically significant. 


\section{Results}

Microarray analysis of differentially expressed genes in HONE1-LMP1 cell line

As shown in Figure 1, the HONE1 cell line stably transfected with the B95.8-LMP1 plasmid showed up-regulation of NF- $\mathrm{kB}$ pathway downstream genes $\mathrm{p}-\mathrm{I} \kappa \mathrm{B} \alpha$ and $\mathrm{p}-$ NF- $\mathrm{kB}$ (2.5-fold), and PARP and survivin (1.4-fold), while down-regulation of PTEN was observed (0.5-fold).

A total of 1533 genes were differentially expressed (1034 up-regulated genes and 499 down-regulated genes) in the HONE1-LMP1-transfected cells compared to those transfected with the control HONE1-Vector. Using the KEGG database, we determined that these genes clustered in several signaling pathways, including the insulin, MAPK, Wnt, TGF-beta, Notch and mTOR signaling pathways, and apoptosis. Five of the differentially expressed genes involved in the mTOR signaling pathway were validated by Q-RT-PCR (Figure 2).

LMP1-regulated genes in mTOR signaling in NPC cell lines LMP1 expression increased by 2.9-fold in HONE1 cells stably transfected with pZipNeoSV-LMP1, as measured

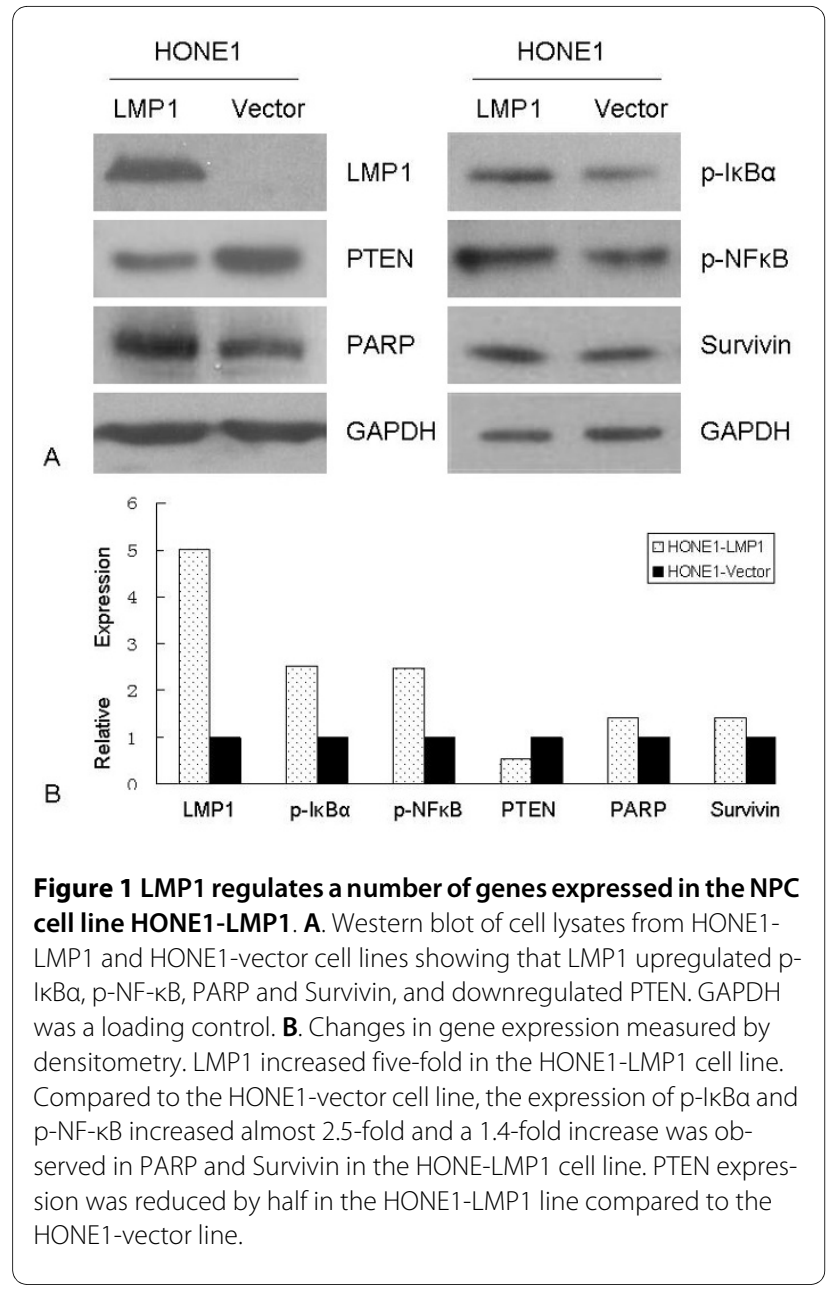

by immunoblot. The p-AKT and p-mTOR genes, upstream in the mTOR signal pathway, were upregulated in 1.6-fold and 1.9-fold, respectively. The downstream genes p-P70S6K and p-4EBP1 were also upregulated, by 1.5-fold and 1.3-fold, respectively. When LMP1 was transiently transfected into the NPC cell line 6-10B, up-regulation of p-AKT was 1.3-fold, p-mTOR was 1.5-fold, pP70S6K was 1.2 -fold, and p-4EBP1 was 1.4 -fold, consistent with results from the HONE1-LMP1 cell line (Figure 3). Immunofluorescence in the EBV-positive NPC cell line C666-1 revealed that after LMP1 knockdown with siRNA at $50 \mathrm{~nm}$ or $100 \mathrm{~nm}, \mathrm{LMP} 1, \mathrm{p}-\mathrm{mTOR}$ and p-4EBP1 were significantly deregulated compared to the C666-1NC-siRNA cell line (Figure 4).

\section{Correlation of expression of LMP1, mTOR signaling pathway genes and clinicopathology of NPC patients}

Representative IHC staining and hematoxylin-eosin (H\&E) staining of NPC tumour is shown in Figure 5. In NPC tissue with LMP1 overexpression, high levels of $\mathrm{p}$ mTOR, p-P70S6K and p-4EBP1 were observed (Figure $5 B-E)$. However, in NPC tissue with low LMP1 expression, p-mTOR, p-P70S6K and p-4EBP1 were also expressed at low levels (Figure 5G-J).

IHC staining showed membrane- and cytoplasm-positive LMP1 staining in NPC tumor cells (Figure 5B). Of the informative 224 cases, 141 (62.9\%) presented with highexpression, and $83(37.1 \%)$ presented with low LMP1 expression. Staining for p-mTOR was cytoplasmic in NPC tumor cells (Figure 5C). Of the informative 223 cases, 109 (48.9\%) presented with high-expression, and $114(51.1 \%)$ presented with low p-mTOR expression.

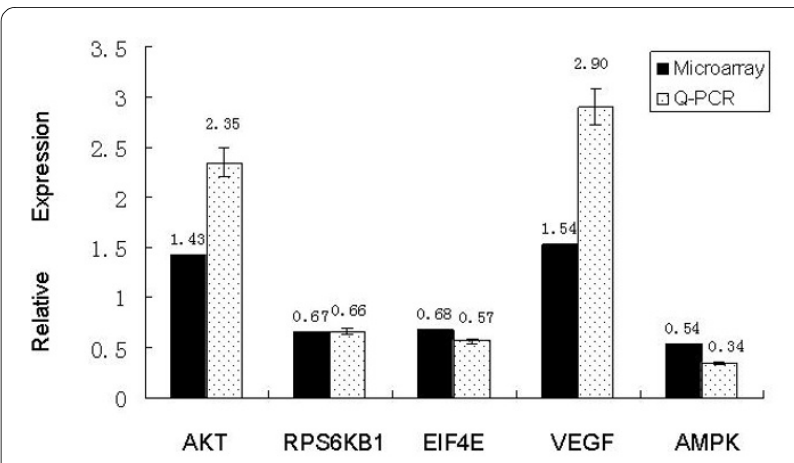

Figure 2 Differentially expressed genes identified by microarray validated by Q-RT-PCR. Five differentially expressed mTOR signaling pathway genes identified by microarray were validated by Q-RT-PCR. The numerical value above each bar is the mean alteration of the gene by microarray analysis or Q-RT-PCR. AKT and VEGF were both up-regulated, and RPS6KB1, EIF4E and AMPK were all down-regulated in the HONE1-LMP1 cell line. Q-RT-PCR analysis of these genes was normalized to GAPDH, and repeated three times independently. The mean and standard deviation are shown. 


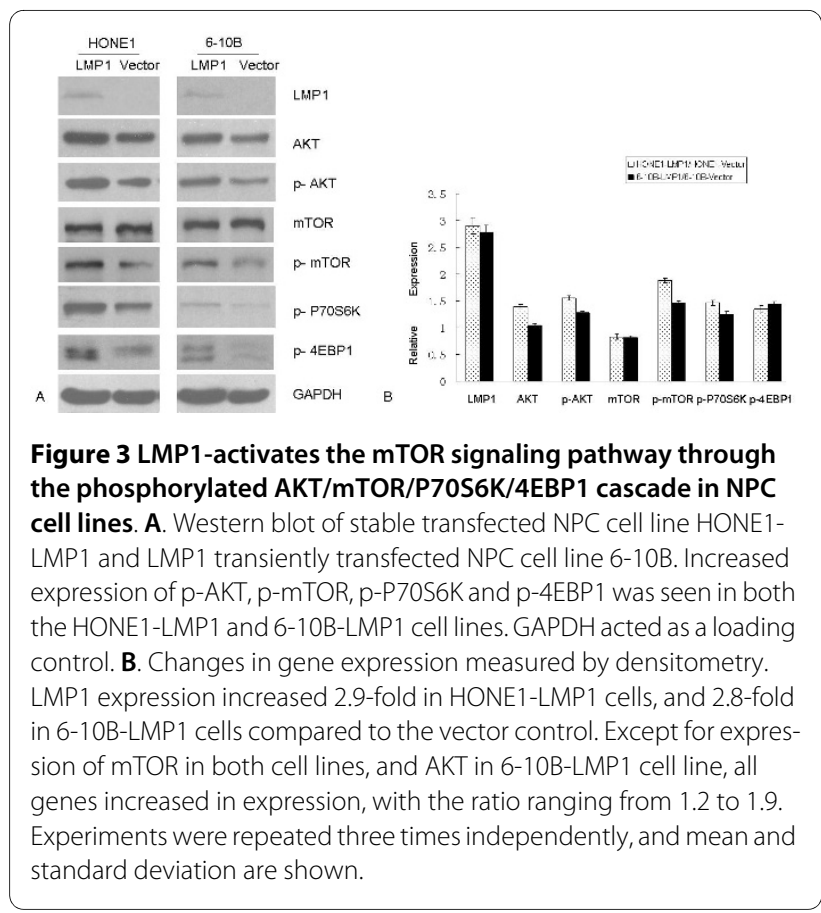

Staining of p-P70S6K was cytoplasmic in NPC tumor cells (Figure 5D). Of the informative 224 cases, 106 (47.3\%) expressed p-P70S6K at high levels, and 118 (52.7\%) showed low expression. Positive staining of p4EBP1 was seen mainly in the cytoplasm of NPC tumor cells (Figure 5E). Of the informative 223 cases, 128 (57.4\%) presented with high-expression, and 95 (42.6\%) of NPC presented with low expression of p-4EBP1.

A significant correlation was found between high pmTOR expression and lymph node metastasis $(p=0.004)$ and recurrence $(p=0.021)$. High expression of p-P70S6K showed a positive correlation with distant metastasis $(p=$

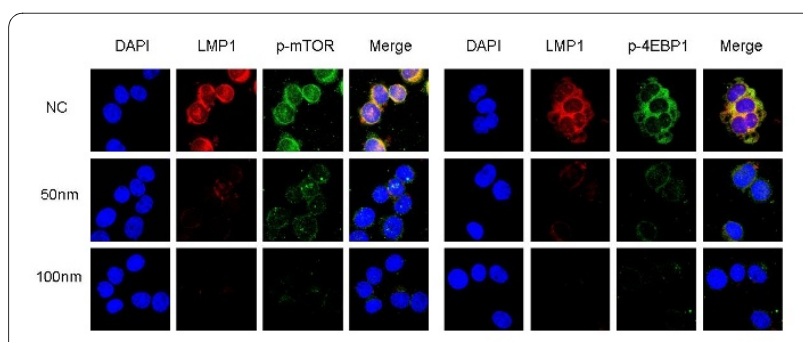

Figure 4 LMP1 silencing reduced $p-m T O R$ and $p-4 E B P 1$ expression in the C666-1 line. C666-1 cells were harvested for immunofluoresence after $72 \mathrm{~h}$ LMP1-siRNA transfection at a final concentration of 50 or $100 \mathrm{~nm}$. Negative control (NC)-siRNA acted as an internal standard. LMP1 expression was in the membrane and cytoplasm, with $\mathrm{p}$ mTOR and p-4EBP1. The location of LMP1 and p-mTOR or p-4EBP1 in the C666-1 cell line overlapped perfectly. When LMP1 expression was decreased with $50 \mathrm{~nm}$ siRNA in C666-1 cells, expression of p-mTOR and $\mathrm{p}-4 \mathrm{EBP} 1$ was also reduced. No detectable $\mathrm{p}-\mathrm{mTOR}$ or $\mathrm{p}-4 \mathrm{EBP} 1$ expression was observed when LMP1 was completely silenced by $100 \mathrm{~nm}$ siRNA in C666-1 cells.

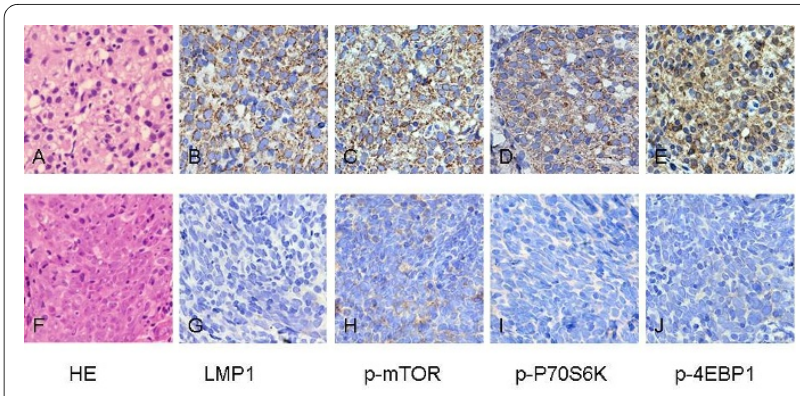

Figure 5 Immunohistochemistry for LMP1, p-mTOR, p-P70S6K and p-4EBP1 in NPC biopsies. Two representative NPC tissues are shown (200X), one in $\mathbf{A}$ to $\mathbf{E}$, and another in frame $\mathbf{F}$ to $\mathbf{J}$. Frames $\mathbf{A}$ and $\mathbf{F}$ are hematoxylin-eosin (H\&E) staining. Positive immunostaining of LMP1 in the membrane and cytoplasm is in frame $\mathbf{B}$, and expression of p-mTOR, p-P70S6K and p-4EBP1 with cytoplasm staining is in C, D, E, respectively. Samples with strong LMP1 expression also presented high levels of p-mTOR, p-P70S6K and p-4EBP1 (B, C, D and E), while samples with no LMP1 expression showed very weak or no expression of p-mTOR, p-P70S6K and p-4EBP1 (G, H, I and $\mathbf{J}$ ).

0.033). High expression of p-4EBP1 correlated with lymph node metastasis $(p=0.045)$. No significant correlation was observed between LMP1 expression and gender, age, WHO type, clinical stage, recurrence, or distant metastasis (Additional file 2). Spearman's correlation analysis revealed that in NPC tumors, LMP1 expression positively correlated with expression of p-mTOR $(r=$ $0.359, p<0.001)$, p-P70S6K $(r=0.293, p<0.001)$, and $\mathrm{p}-$ 4EBP1 $(r=0.290, p<0.001)$ (Table 1$)$.

\section{Correlation between LMP1 and mTOR expression and NPC prognosis}

The overall 5-year-survival rate of the $230 \mathrm{NPC}$ patients was $60 \%$, and the 10 -year-survival rate was $38 \%$. When the patient cohort was stratified by LMP 1 expression, the 5 -year overall survival rate in patients with high LMP1 expression $(\mathrm{n}=141)$ was $54 \%$, and with low LMP1 expression $(n=83)$, it was $68 \%$. The two groups showed a significant difference ( $p=0.020$, Figure 6A). For p-mTOR expression, the 5 -year overall survival rates in NPC patients with high expression $(\mathrm{n}=109)$ was $55 \%$, and was $62 \%$ for patients with low expression $(\mathrm{n}=114)$, with no significant difference between the two groups ( $p=0.311$, Figure 6B). For p-P70S6K expression, the 5-year overall survival rate for NPC patients with high expression $(\mathrm{n}=$ 106) was $49 \%$, and for low expression $(\mathrm{n}=118)$ it was $69 \%$, with a significant difference between the two groups $(p=0.049$, Figure $6 \mathrm{C})$. For $\mathrm{p}-4 \mathrm{EBP} 1$, the 5-year overall survival rates in patients with high expression $(\mathrm{n}=128)$ was $49 \%$, and for low expression $(n=95)$ it was $71 \%$, with a significant difference between the groups $(p=0.010$, Figure 6D).

Univariate analysis showed gender, age, clinical stage, metastasis, LMP1 expression and p-4EBP1 expression were prognostic predictors of overall survival in NPC 
Table 1: Correlation between LMP1 and mTOR signaling pathway genes in NPC.

\begin{tabular}{|c|c|c|c|c|c|c|}
\hline & & \multicolumn{2}{|c|}{ LMP1 expression } & \multirow[b]{2}{*}{ Case } & \multirow[b]{2}{*}{$\mathbf{r}$} & \multirow[b]{2}{*}{ P-value } \\
\hline & & Low & High & & & \\
\hline \multirow{3}{*}{$\begin{array}{l}\mathrm{p} \text {-mTOR } \\
\text { expression }\end{array}$} & Low & 60 & 54 & 114 & & \\
\hline & High & 19 & 86 & 105 & 0.359 & $<0.001$ \\
\hline & & & & $n=219$ & & \\
\hline \multirow{3}{*}{$\begin{array}{l}\mathrm{p}-\mathrm{P} 70 \mathrm{S6K} \\
\text { expression }\end{array}$} & Low & 57 & 58 & 115 & & \\
\hline & High & 22 & 81 & 103 & 0.293 & $<0.001$ \\
\hline & & & & $n=218$ & & \\
\hline \multirow{3}{*}{$\begin{array}{l}\mathrm{p}-4 \mathrm{EBP} 1 \\
\text { expression }\end{array}$} & Low & 49 & 44 & 93 & & \\
\hline & High & 31 & 96 & 127 & 0.290 & $<0.001$ \\
\hline & & & & $n=220$ & & \\
\hline
\end{tabular}

patients (Table 2). Multivariate Cox regression analysis indicated that high expression of LMP1, gender and metastasis, were independent prognostic factors in the NPC patients, but mTOR signaling pathway genes were not (Table 2).

\section{Discussion}

Previous studies reported that LMP1 is involved in several signaling pathways including NF- $\mathrm{BB}, \mathrm{AP}-1, \mathrm{JAK} /$ STAT, PI3K/AKT and ERK-MAPK and regulate their downstream effects [6-9]. LMP1 activate the PI3K/AKT/ mTOR signaling pathway in B lymphocytes [21], and the mTOR signaling pathway has been identified as a downstream component of the PI3K/AKT pathway in the LMP2A-transfected NPC cell lines HONE1 and AD/AH [22]. The mTOR signaling pathway might positively regulate cyclin D1 expression in NPC [23]. In this study, microarray analysis of the NPC HONE1 cell line stably transfected with LMP1 identified several differentially expressed genes of mTOR signaling pathways. This is the first report that LMP1 can regulate the mTOR signaling pathway in NPC. Furthermore, LMP1 overexpression and knockdown studies confirmed that LMP1-regulated genes are involved in the mTOR signaling pathway, and LMP1 expression was essential for the activation of $p$ mTOR and p-4EBP1 in NPC cell lines. In addition, our in vitro studies found that LMP1 expression positively correlated with overexpression of $\mathrm{p}-\mathrm{mTOR}, \mathrm{p}-\mathrm{P} 70 \mathrm{S6K}$ and $\mathrm{p}$ 4EBP1 in NPC tumors.

As a well-known oncogene, one of the functions of LMP1 is to promote cell proliferation in NPC $[24,25]$. The mTOR signaling pathway is also a major effector in cell growth, cell proliferation and cell survival, through regulation of protein synthesis, while P70S6K and 4EBP1 play particularly important roles in the mTOR signaling pathway growth acceleration function [10]. In this study, our findings suggest that activation of P70S6K and 4EBP1 requires LMP1, and that when these genes are phosphorylated by LMP1, activated P70S6K and 4EBP1 initiate a sequence of events that promotes protein synthesis, cell growth and proliferation. Further studies need to be done to investigate the mechanism by which LMP1 regulates mTOR signaling in NPC tumorigenesis.

Deregulation of the mTOR signaling pathway is reported in many malignancies, and some of the signaling molecules in this pathway are predictors of prognosis in different types of cancers. Cytoplasmic p-mTOR expression correlates with poorer survival in gastric cancer and cervix adenocarcinoma [26,27]. High expression of $p$ mTOR, p-P70S6K and p-4EBP1 correlate with poor outcome in glioblastoma [28], and p-4EBP1 was demonstrated to be a potential prognostic factor in breast cancer and an independent prognostic marker in ovarian cancer $[29,30]$. Our results revealed that NPC patients with high p-P70S6K and p-4EBP1 expression had a significantly shorter overall survival than those with low $\mathrm{p}-\mathrm{P} 70 \mathrm{~S} 6 \mathrm{~K}$ ( $p$ $=0.049)$ and $\mathrm{p}-4 \mathrm{EBP} 1(p=0.010)$ expression. These results are in accordance with previous studies on malignancies. p-P70S6K is required for 5'-TOP mRNA translation, especially translation of all ribosomal proteins, elongation factors, and poly (A)-binding protein. 4EBP1 forms a complex with eIF4E by closely interaction, and once 4EBP1 is phosphorylated, 4EBP1 loses its high affinity for eIF4E. When eIF4E dissociates, activated 4EBP1 enhances protein synthesis $[11,12]$. High expression of pP70S6K and p-4EBP1 in NPC tissues might result in a high level of protein synthesis and cell proliferation, and the poor prognosis of the NPC patients. 


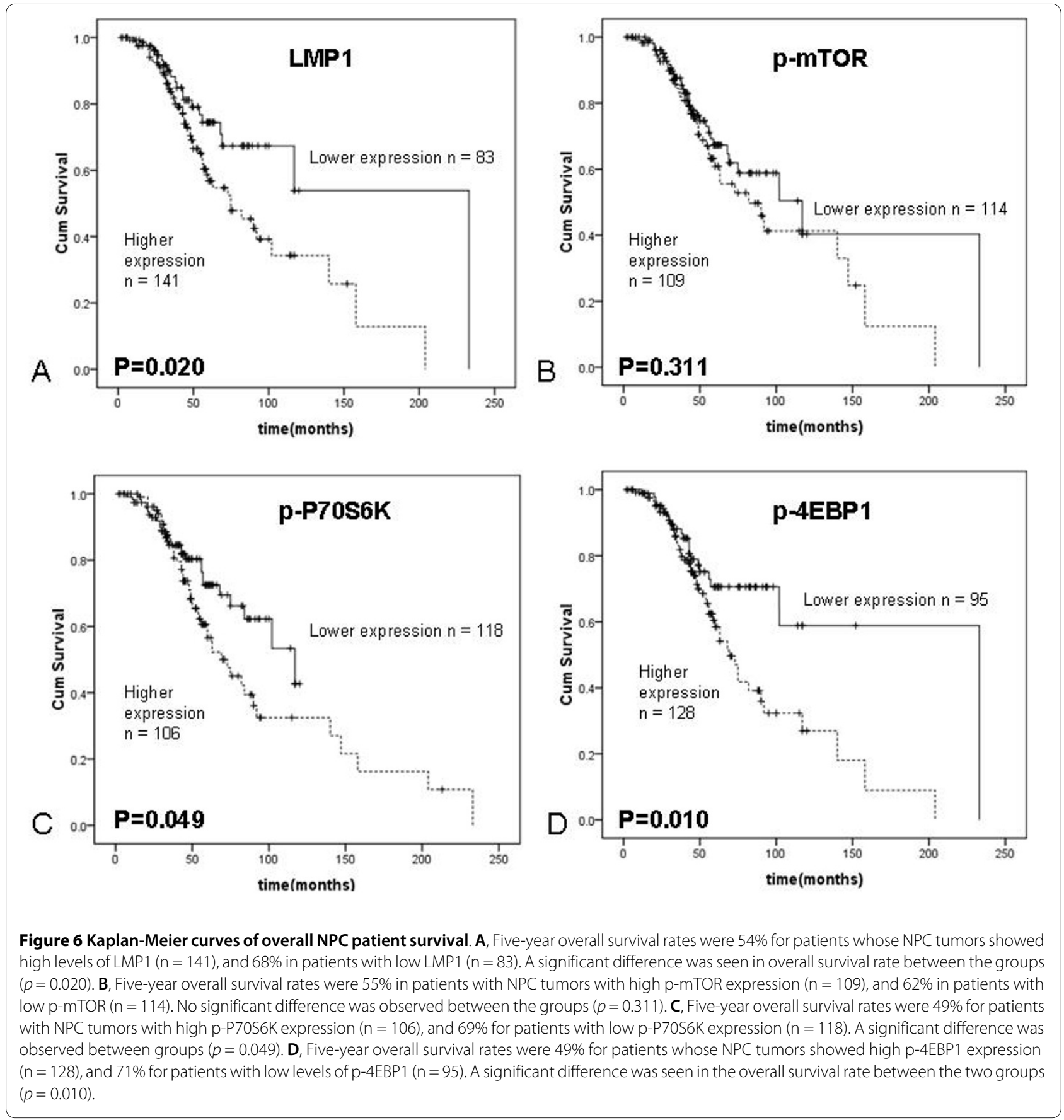

In this study, a large sample size of NPC cases were used for IHC staining of LMP1, and LMP1 overexpression was detected in $62.9 \%(141 / 224)$ of NPC tumors, in accordance with previous studies [31-33]. Interestingly, we found that LMP1 overexpression in NPC patients was significantly associated with poorer overall survival $(p=$ 0.020). This result differed from previous reports, which found that LMP1 overexpression suggested a better prognosis of NPC patients [34], and LMP1 was not an effective indicator of NPC outcomes [35]. The possible reasons for the differences might be different sample sizes, regional distribution, or different LMP1 variants. Compared to previous studies, our study had a larger sample size for LMP1 expression and NPC prognosis.

Although high-expression of LMP1, p-P70S6K and p4EBP1 was associated with poor survival of NPC patients, multivariate analysis revealed that only LMP1 expression $(p=0.013)$, as well as gender $(p=0.014)$ and metastasis $(p=0.003)$, were independent prognostic factors. We found that the mTOR signaling pathway was triggered by LMP1, suggesting that LMP1 may have more 
Table 2: Univariate and multivariate analysis of Cox proportional hazards model in NPC.

\begin{tabular}{|c|c|c|c|}
\hline Characristics & Hazard ratio & $95 \% \mathrm{Cl}$ & P-value \\
\hline \multicolumn{4}{|l|}{ Univariate analysis } \\
\hline Gender (male vs. female) & 0.422 & $0.232-0.770$ & $0.005^{*}$ \\
\hline Age (<46 vs. $\geq 46)$ & 1.721 & $1.085-2.729$ & $0.021^{*}$ \\
\hline WHO type (I vs. IV) & 1.025 & $0.618-1.700$ & 0.925 \\
\hline $\begin{array}{l}\text { Clinical stage (I + II vs. III + } \\
\text { IV) }\end{array}$ & 1.824 & $1.012-3.286$ & $0.045^{*}$ \\
\hline T stage (T1 2 vs. T3 4) & 1.571 & $0.972-2.540$ & 0.065 \\
\hline $\mathrm{N}$ stage (N0 vs. N1 3) & 0.936 & $0.568-1.544$ & 0.796 \\
\hline Recurrence (no vs. yes) & 1.442 & $0.895-2.322$ & 0.132 \\
\hline Metastasis (no vs. yes) & 2.466 & $1.412-4.304$ & $0.002^{*}$ \\
\hline $\begin{array}{l}\text { LMP1 expression (low vs. } \\
\text { high) }\end{array}$ & 1.863 & $1.091-3.183$ & $0.023^{*}$ \\
\hline $\begin{array}{l}\text { p-mTOR expression (low } \\
\text { vs. high) }\end{array}$ & 1.274 & $0.796-2.040$ & 0.314 \\
\hline $\begin{array}{l}\text { p-P70S6K expression (low } \\
\text { vs. high) }\end{array}$ & 1.447 & $0.907-2.309$ & 0.121 \\
\hline $\begin{array}{l}\text { p-4EBP1 expression (low } \\
\text { vs. high) }\end{array}$ & 1.920 & $1.154-3.195$ & $0.012^{*}$ \\
\hline \multicolumn{4}{|l|}{ Multivariate analysis } \\
\hline Gender (male vs. female) & 0.447 & $0.234-0.851$ & $0.014^{*}$ \\
\hline Metastasis (no vs. yes) & 2.591 & $1.383-4.856$ & $0.003^{*}$ \\
\hline $\begin{array}{l}\text { LMP1 expression (low vs. } \\
\text { high) }\end{array}$ & 2.056 & $1.161-3.641$ & $0.013^{*}$ \\
\hline
\end{tabular}

* Statistically significant difference.

important roles than mTOR signaling molecules in the carcinogenesis and development of NPC.

\section{Conclusions}

In summary, we present the first report that LMP1-regulated genes are involved in the mTOR signaling pathway, and LMP1 expression is essential for the activation of the mTOR signaling pathway in NPC. LMP1 activates the $\mathrm{AKT} / \mathrm{mTOR} / \mathrm{P} 70 \mathrm{S6K} / 4 \mathrm{EBP} 1$ axis in NPC tumors, and high expression of LMP1, p-P70S6K and p-4EBP1 predict poor prognosis of NPC patients.

\section{Additional material}

Additional file $\mathbf{1}$ Table for primers used in the study. The table shows the primers of five genes associated with the mTOR signaling pathway which were designed by Primer 5.0.

Additional file 2 Correlation between LMP1, p-mTOR, p-P70S6K, p4EBP1 and clinicopathological parameters of NPC. The table shows the correlation between the expression of LMP1, p-mTOR, p-P70S6K, p-4EBP1 and clinicopathological parameters of NPC (including gender, age, WHO type, TNM stage, T stage, N stage, recurrence and metastasis).
Competing interests

The authors declare that they have no competing interests.

\section{Authors' contributions}

JC carried out substantial experimental work and drafted the manuscript. JYS designed the research and supervised the study. CFH was responsible for the patient samples and tissue array construction. JHH and QS supported the work of IHC. LXY supported the lab work. XFZ and YXZ helped finalize the research design. All authors read and approved the final manuscript.

\section{Acknowledgements}

This work was supported in part by the National High Technology Research and Development Program of China (863 Program) (No. 20060102A4002), the Chinese State Key Basic Research Project (No.2004CB518708). A grant from the Ministry of Education Program for New Century Excellent Talents in University (NCET), 985-II Project.

\section{Author Details}

1State Key Laboratory of Oncology in Southern China, Sun Yat-Sen University Cancer Center, Guangzhou, China, ²Department of Pathology, Sun Yat-Sen University Cancer Center, Guangzhou, China, 3Department of Microbiolgy, Tumor and Cell Biology, Karolinska Institutet, Box 280, Stockholm SE-17177, Sweden, ${ }^{4}$ Institute of Cancer Studies, University of Birmingham, Birmingham, UK, B15 2TT, UK and ${ }^{5}$ Department of Experiment Research, Sun Yat-Sen University Cancer Center, Guangzhou, China

Received: 5 November 2009 Accepted: 26 March 2010 Published: 26 March 2010 


\section{References}

1. Busson P, Keryer C, Ooka T, Corbex M: EBV-associated nasopharyngeal carcinomas: from epidemiology to virus-targeting strategies. Trends in microbiology 2004, 12(8):356-360.

2. Chan AT, Teo PM, Johnson PJ: Nasopharyngeal carcinoma. Ann Oncol 2002, 13(7):1007-1015.

3. Young LS, Murray PG: Epstein-Barr virus and oncogenesis: from latent genes to tumours. Oncogene 2003, 22(33):5108-5121.

4. Tsao SW, Tramoutanis G, Dawson CW, Lo AK, Huang DP: The significance of LMP1 expression in nasopharyngeal carcinoma. Seminars in cancer biology 2002, 12(6):473-487.

5. Yoshizaki T, Sato H, Murono S, Pagano JS, Furukawa M: Matrix metalloproteinase 9 is induced by the Epstein-Barr virus BZLF1 transactivator. Clinical \& experimental metastasis 1999, 17(5):431-436.

6. Zheng H, Li LL, Hu DS, Deng XY, Cao Y: Role of Epstein-Barr virus encoded latent membrane protein 1 in the carcinogenesis of nasopharyngeal carcinoma. Cellular \& molecular immunology 2007, 4(3):185-196.

7. Mainou BA, Everly DN Jr, Raab-Traub N: Epstein-Barr virus latent membrane protein 1 CTAR1 mediates rodent and human fibroblast transformation through activation of PI3K. Oncogene 2005, 24(46):6917-6924.

8. Dawson CW, Tramountanis G, Eliopoulos AG, Young LS: Epstein-Barr virus latent membrane protein 1 (LMP1) activates the phosphatidylinositol 3-kinase/Akt pathway to promote cell survival and induce actin filament remodeling. The Journal of biological chemistry 2003, 278(6):3694-3704

9. Dawson CW, Laverick L, Morris MA, Tramoutanis G, Young LS: Epstein-Barr virus-encoded LMP1 regulates epithelial cell motility and invasion via the ERK-MAPK pathway. Journal of virology 2008, 82(7):3654-3664.

10. Tsang CK, Qi H, Liu LF, Zheng XF: Targeting mammalian target of rapamycin (mTOR) for health and diseases. Drug discovery today 2007, 12(3-4):112-124.

11. Goberdhan DC, Boyd CA: mTOR: dissecting regulation and mechanism of action to understand human disease. Biochemical Society transactions 2009, 37(Pt 1):213-216.

12. Hay N, Sonenberg N: Upstream and downstream of mTOR. Genes \& development 2004, 18(16):1926-1945.

13. Min H, Hong M, Ma J, Zhang E, Zheng Q, Zhang J, Zhang J, Zhang F, Su Y, Qiu F: A new staging system for nasopharyngeal carcinoma in China. International journal of radiation oncology, biology, physics 1994, 30(5):1037-1042.

14. Li YH, Hu CF, Shao Q, Huang MY, Hou JH, Xie D, Zeng YX, Shao JY: Elevated expressions of survivin and VEGF protein are strong independent predictors of survival in advanced nasopharyngeal carcinoma. Journal of translational medicine 2008, 6:1.

15. Lan K, Ren CP XL, He ZW, Gan RL, Yao KT: Comparison Study on Tumorigenicity of Two Different LMP1 Isolates. Chinese Journal of Cancer 2001, 20(10):1033-1037.

16. Yu J, Zhang L, Chen A, Xiang G, Wang Y, Wu J, Mitchelson K, Cheng J, Zhou $Y$ : Identification of the gene transcription and apoptosis mediated by TGF-beta-Smad2/3-Smad4 signaling. Journal of cellular physiology 2008, 215(2):422-433

17. Yang YH, Dudoit S, Luu P, Lin DM, Peng V, Ngai J, Speed TP: Normalization for CDNA microarray data: a robust composite method addressing single and multiple slide systematic variation. Nucleic acids research 2002, 30(4):e15.

18. Livak KJ, Schmittgen TD: Analysis of relative gene expression data using real-time quantitative PCR and the 2(-Delta Delta C(T)) Method. Methods (San Diego, Calif) 2001, 25(4):402-408.

19. Li J, Zhang XS, Xie D, Deng HX, Gao YF, Chen QY, Huang WL, Masucci MG, Zeng YX: Expression of immune-related molecules in primary EBVpositive Chinese nasopharyngeal carcinoma: associated with latent membrane protein 1 (LMP1) expression. Cancer biology \& therapy 2007, 6(12):1997-2004.

20. Mei YP, Zhu XF, Zhou JM, Huang $H$, Deng $R$, Zeng YX: siRNA targeting LMP1-induced apoptosis in EBV-positive lymphoma cells is associated with inhibition of telomerase activity and expression. Cancer letters 2006, 232(2):189-198.

21. Lambert SL, Martinez OM: Latent membrane protein 1 of EBV activates phosphatidylinositol 3-kinase to induce production of IL-10. J Immunol 2007, 179(12):8225-8234.
22. Moody CA, Scott RS, Amirghahari N, Nathan CA, Young LS, Dawson CW, Sixbey JW: Modulation of the cell growth regulator mTOR by EpsteinBarr virus-encoded LMP2A. Journal of virology 2005, 79(9):5499-5506.

23. Huang XM, Dai CB, Mou ZL, Wang LJ, Wen WP, Lin SG, Xu G, Li HB: Overproduction of cyclin D1 is dependent on activated mTORC1 signal in nasopharyngeal carcinoma: implication for therapy. Cancer letters 2009, 279(1):47-56.

24. Li HM, Zhuang ZH, Wang Q, Pang JC, Wang XH, Wong HL, Feng HC, Jin DY, Ling MT, Wong YC, et al.: Epstein-Barr virus latent membrane protein 1 (LMP1) upregulates Id1 expression in nasopharyngeal epithelial cells. Oncogene 2004, 23(25):4488-4494

25. Faqing T, Zhi H, Liqun Y, Min T, Huanhua G, Xiyun D, Ya C: Epstein-Barr virus LMP1 initiates cell proliferation and apoptosis inhibition via regulating expression of Survivin in nasopharyngeal carcinoma. Experimental oncology 2005, 27(2):96-101.

26. Murayama T, Inokuchi M, Takagi Y, Yamada H, Kojima K, Kumagai J, Kawano T, Sugihara K: Relation between outcomes and localisation of p-mTOR expression in gastric cancer. British journal of cancer 2009, 100(5):782-788.

27. Faried LS, Faried A, Kanuma T, Aoki H, Sano T, Nakazato T, Tamura T, Kuwano H, Minegishi T: Expression of an activated mammalian target of rapamycin in adenocarcinoma of the cervix: A potential biomarker and molecular target therapy. Molecular carcinogenesis 2008, 47(6):446-457.

28. Pelloski CE, Lin E, Zhang L, Yung WK, Colman H, Liu JL, Woo SY, Heimberger AB, Suki D, Prados M, et al:: Prognostic associations of activated mitogen-activated protein kinase and Akt pathways in glioblastoma. Clin Cancer Res 2006, 12(13):3935-3941.

29. Rojo F, Najera L, Lirola J, Jimenez J, Guzman M, Sabadell MD, Baselga J, Ramon y, Cajal S: 4E-binding protein 1, a cell signaling hallmark in breast cancer that correlates with pathologic grade and prognosis. Clin Cancer Res 2007, 13(1):81-89.

30. Castellvi J, Garcia A, Rojo F, Ruiz-Marcellan C, Gil A, Baselga J, Ramon y, Cajal S: Phosphorylated 4E binding protein 1: a hallmark of cell signaling that correlates with survival in ovarian cancer. Cancer 2006, 107(8):1801-1811

31. Horikawa T, Sheen TS, Takeshita H, Sato H, Furukawa M, Yoshizaki T: Induction of c-Met proto-oncogene by Epstein-Barr virus latent membrane protein-1 and the correlation with cervical lymph node metastasis of nasopharyngeal carcinoma. The American journal of pathology 2001, 159(1):27-33.

32. Jeon YK, Lee BY, Kim JE, Lee SS, Kim CW: Molecular characterization of Epstein-Barr virus and oncoprotein expression in nasopharyngeal carcinoma in Korea. Head \& neck 2004, 26(7):573-583.

33. Shao JY, Ernberg I, Biberfeld P, Heiden T, Zeng YX, Hu LF: Epstein-Barr virus LMP1 status in relation to apoptosis, p53 expression and leucocyte infiltration in nasopharyngeal carcinoma. Anticancer research 2004, 24(4):2309-2318

34. Hu LF, Chen F, Zhen QF, Zhang YW, Luo Y, Zheng X, Winberg G, Ernberg I, Klein G: Differences in the growth pattern and clinical course of EBVLMP1 expressing and non-expressing nasopharyngeal carcinomas. Eur J Cancer 1995, 31A(5):658-660

35. Sarac S, Akyol MU, Kanbur B, Poyraz A, Akyol G, Yilmaz T, Sungur A: Bcl-2 and LMP1 expression in nasopharyngeal carcinomas. American journal of otolaryngology 2001, 22(6):377-382.

doi: $10.1186 / 1479-5876-8-30$

Cite this article as: Chen et al., Epstein-Barr virus encoded latent membrane protein 1 regulates mTOR signaling pathway genes which predict poor prognosis of nasopharyngeal carcinoma Journal of Translational Medicine 2010 8:30 